\title{
Frost susceptibility of sub-base gravel used in Pearl-Chain Bridges: an experimental investigation
}

Lund, Mia Schou Møller; Hansen, Kurt Kielsgaard; Andersen, Iben Brøndum

Published in:

The International Journal of Pavement Engineering

Link to article, DOI:

10.1080/10298436.2016.1230429

Publication date:

2018

Document Version

Peer reviewed version

Link back to DTU Orbit

Citation (APA):

Lund, M. S. M., Hansen, K. K., \& Andersen, I. B. (2018). Frost susceptibility of sub-base gravel used in Pearl-

Chain Bridges: an experimental investigation. The International Journal of Pavement Engineering, 19(11), 986998. https://doi.org/10.1080/10298436.2016.1230429

\section{General rights}

Copyright and moral rights for the publications made accessible in the public portal are retained by the authors and/or other copyright owners and it is a condition of accessing publications that users recognise and abide by the legal requirements associated with these rights.

- Users may download and print one copy of any publication from the public portal for the purpose of private study or research.

- You may not further distribute the material or use it for any profit-making activity or commercial gain

- You may freely distribute the URL identifying the publication in the public portal 
To appear in the International Journal of Pavement Engineering

Vol. 00, No. 00, 00 Month 20XX, 1-22

\title{
Frost Susceptibility of Sub-base Gravel used in Pearl-Chain Bridges: An Experimental Investigation
}

\author{
M.S.M. Lund ${ }^{\mathrm{a} *}$, K.K. Hansen ${ }^{\mathrm{a}}$ and I.B. Andersen ${ }^{\mathrm{a}}$ \\ ${ }^{a}$ Technical University of Denmark, Brovej 118, DK-2800 Kgs. Lyngby, Denmark
}

( $v 1.0$ released October 2015$)$

\begin{abstract}
This study investigates frost susceptibility of sub-base gravel determined by the ASTM D5918-13 standard as a conservative estimate of the frost heave risk of fill in overfilled arch bridges, particularly in Pearl-Chain Bridges. Frost heave of granular materials has been of great research interest from the end of the 1920's until the present day. Most new literature relates to empirical results that are several decades old. This is also the case for Danish tender specifications according to which the frost susceptibility of a sub-base gravel is solely assessed from its fines content. However, no actual frost tests have been carried out to verify this assumption. In the present study, the frost susceptibility of four different Danish gravel materials is categorized from their heave rate. We test two Danish sub-base gravel materials, with particle size distributions of $0-8 \mathrm{~mm}$ and $0-31.5 \mathrm{~mm}$, respectively, and also two modified sub-base gravel materials with increased and reduced fines contents. The fines content of the gravel materials is analyzed by laser diffraction, and compared with two common frost susceptibility criteria, Casagrande's and Schaible's, and with Danish tender specifications. Even though the two sub-base gravel materials are expected to be frost safe, 0-31.5 $\mathrm{mm}$ sub-base gravel shows medium frost susceptibility, whereas $0-8 \mathrm{~mm}$ sub-base gravel shows negligible frost susceptibility. The gravel materials with increased and reduced fines content are categorized as having low to medium frost susceptibility and low frost susceptibility, respectively. The permeability of the gravel materials is determined, and the permeability coefficient of $0-31.5 \mathrm{~mm}$ sub-base gravel is five times greater than that of $0-8 \mathrm{~mm}$ sub-base gravel. The results suggest that the criterion used to classify the frost susceptibility of Danish sub-base gravel materials based solely on their fines content is insufficient, and that the permeability coefficient should also be considered.
\end{abstract}

Keywords: fill material; frost susceptibility; Pearl-Chain Bridge; permeability; sub-base gravel

\section{Introduction}

Typical fill materials in overfilled arch bridges are granular materials such as soil and gravel. There are several examples of modern prefabricated arch bridge systems with gravel fill, such as the TechSpan bridge system (Hutchinson 2004), and the BEBO arch system (BEBO Arch Systems 2009), but older arch bridge constructions are also usually filled with a granular material (Sihwa 1987). Apart from the low cost, the main reason for the widespread use of this type of fill is that granular materials are expected to satisfy typical main functions of fill materials in arch bridges, such as stabilization of the arch structure, transfer of traffic loads to the arch, and overall durability of the fill material itself.

In areas where the temperature annually varies around the freezing point, a bridge is a critical part of the construction of a road because it is exposed to freezing from below, from above and from the sides. This also means that the fill material is considerably affected by freezing and thawing. Therefore, to prevent any damage of the bridge superstructure, it is important to ensure sufficient freeze-thaw durability of the fill material. Under the right circumstances some

*Corresponding author. Email: msml@byg.dtu.dk 
gravel materials are known to suffer from frost heaving, which among other things exerts high pressure on the spandrel walls (Sihwa 1987). Frost heaving also causes cracks in the wearing course, and thereby deterioration of the bridge. There are several examples of old arch bridges that have been strengthened by replacing old granular fill with concrete fill (Sihwa 1987).

Frost heave is caused by the formation of ice lenses in soil. When the temperature of the surrounding air, typically above the soil, falls below zero, ice crystals form and coalesce into ice lenses, thereby initiating a freezing front that descends through the soil (Anderson et al. 1984). The ice lenses grow because of water migration to the freezing front from a water supply below the soil. Eventually the growth of ice lenses results in frost heaving, causing an upward displacement of the soil equal to the thickness of the ice (Taber 1929). For the ice lenses to grow, the ice has to be segregated from the soil particles. A pre-melted liquid water film around the soil particles caused by ice-particle interaction separates the ice from the soil particles, and the growth of the segregated ice increases due to these water films working as water supplying passages (Beskow 1935; Rempel 2007). Intermolecular forces across these thin water films create a fluid pressure gradient, causing the unfrozen water to be transported to the freezing zone (Rempel 2007, 2010). The theoretical understanding of the mechanisms driving frost heaving is complex, and many incorrect theories have been postulated throughout the last century. One of the most common misunderstandings is that capillary forces transport water from the water source to the freezing zone (Rempel 2010; Taber 1930). Because of ice segregation, bands of soil-free ice lenses are formed between layers consisting of a mixture of ice, particles and water (Rempel 2007). When the air temperature changes, the temperature gradient changes, and the freezing front changes position, resulting in several bands of ice lenses at different soil depths (Anderson et al. 1984).

Three conditions must exist for frost heaving to occur: the climate should be so cold that the freezing front can be initiated, a water supply should be available, and a soil material that is susceptible to frost should lie within the freezing zone (Anderson et al. 1984). Since the most straightforward approach to eliminate frost heaving is to avoid using frost-susceptible soil, this has been a research field of great interest during the last century. More than 100 different criteria have been proposed to assess whether or not a specific soil material is frost-susceptible (Chamberlain 1981). Two of the most simple and well-known of these are Casagrande's and Schaible's frost criteria, both of which build on a consideration of the soil particle size distribution. The soils being most vulnerable to frost heaving are those being sufficiently fine-grained to allow water to be held in the material, but at the same time being sufficiently coarse-grained to provide the necessary permeability to supply liquid water to the segregated ice (Rempel 2010).

In 1931, Arthur Casagrande proposed the following rule of thumb to determine whether or not a soil type is frost-susceptible:

'Under natural freezing conditions and with sufficient water supply one should expect considerable ice segregation in non-uniform soils containing more than three percent of grains smaller than 0.02 $\mathrm{mm}$, and in very uniform soils containing more than 10 percent smaller than 0.02 mm.' (Casagrande 1931)

In Denmark, non-uniform soils are typically defined as those having a coefficient of uniformity $\left(C_{u}\right)$ greater than 5 , whereas uniform soils have a $C_{u}$ less than 5 (Chamberlain 1981).

In 1957, Lothar Schaible proposed his most recent classification system that divides soils into three categories based on the proportion of particles finer than $0.002 \mathrm{~mm}, 0.02 \mathrm{~mm}$ and 0.1 $\mathrm{mm}$, respectively (Chamberlain 1981). Figure 1 shows Schaible's frost limit curves together with Casagrande's frost criteria.

In Denmark, determination of frost susceptibility is based solely on the particle size characteristic. Danish contractors use Schaible's frost criterion to determine whether or not a gravel material is frost-susceptible (NCC Denmark 2001). The prevalence of this approach is also clear from the Danish tender specification for so-called 'sub-base gravel' materials, that is, gravel materials typically used for capillary breaks. Sub-base gravel materials are considered to lie within the frost safe zone in Figure 1, and are either categorized as 'quality I' or 'quality II' depending 


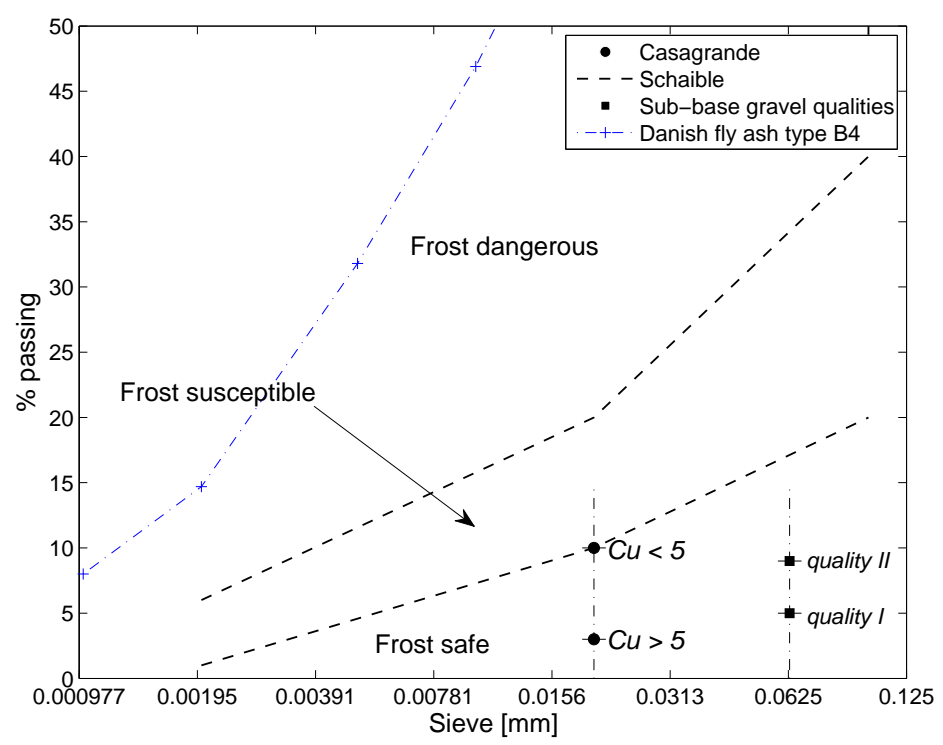

Figure 1. Frost criteria as given by Casagrande and Schaible. The mentioned frost susceptibility classes - 'frost safe', 'frost susceptible' and 'frost dangerous' - relate to Schaible's criterion. Casagrande's criterion distinguishes between soils with coefficients of uniformity less than 5 and greater than 5. For a soil material to be frost-susceptible, the proportion of soil particles at $0.02 \mathrm{~mm}$ needs to lie above the markings. The requirements to the maximum fines content in Danish quality I and quality II sub-base gravel materials are also shown, and the amount of soil particles at 0.063 $\mathrm{mm}$ needs to lie below the markings to fulfill the requirements for the specific quality. Finally, the particle size distribution of Danish fly ash type B4 is shown.

on their particle size distribution (Sub-base of Sand and Gravel - GWS 2003). Neither quality allows particles greater than $90 \mathrm{~mm}$ in diameter, and a maximum of $15 \%$ should be greater than $63 \mathrm{~mm}$ in diameter. A maximum of $5 \%$ of quality I and $9 \%$ of quality II can be less than 63 $\mu \mathrm{m}$ in diameter, which categorizes quality I and quality II sub-base gravel as $\mathrm{UF}_{5}$ and $\mathrm{UF}_{9}$, respectively, according to the Danish standard 13285 (DS Standard 13285 2011). The definition of these requirements is believed to have originated from, and been inspired by, Casagrande's frost criterion (Chamberlain 1981).

Besides the particle size distribution, other methods can be used to determine the frost susceptibility of soils, such as frost heave tests. A large number of different frost heave test variants exist around the world, making it difficult for experts to agree on a single test method. Thus, in Europe it has not been possible to reach agreement on a joint European standard test method, and therefore no such standard exists. However, in 1996 the American Society for Testing and Materials (ASTM) published a standard test method for frost heave and thaw-weakening susceptibility of soils (ASTM Standard D5918-13 2013). This standard is based on the recommendations given in the Cold Regions Research and Engineering Laboratory (CRREL) monograph 81-2 (Chamberlain 1981), in which more than 100 different methods for determining frost susceptibility were reviewed, and four methods were proposed for further evaluation, including one frost heave test.

The original objective of the present study was to demonstrate that two Danish sub-base gravel materials suitable for use as fill in arch bridges, particularly in Pearl-Chain Bridges, were not exposed to frost heaving when tested in accordance with the ASTM D5918-13 standard (ASTM Standard D5918-13 2013). However, as the following sections will show, the results did not come out as expected, and even though sub-base gravels are in general expected to be frost safe, one of the tested sub-base gravels was found to be frost susceptible. The ASTM D5918-13 standard (ASTM Standard D5918-13 2013) is primarily developed to assess the frost susceptibility of soil materials used for pavements. Because the construction of pavements differs significantly 


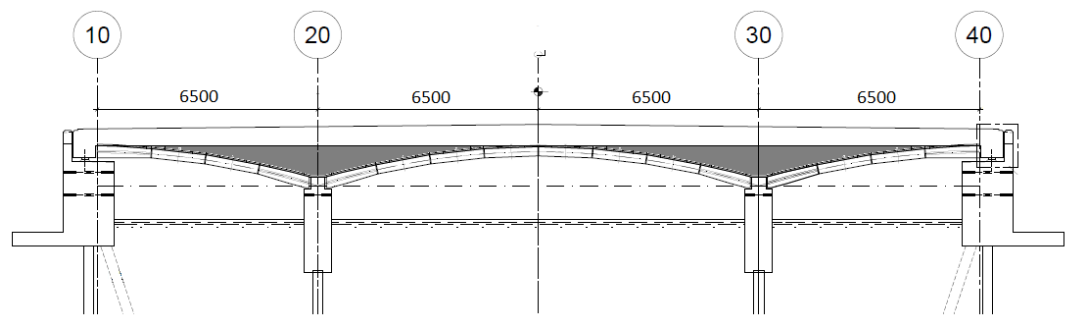

Figure 2. Longitudinal section of the very first Pearl-Chain Bridge constructed in Denmark in 2015. Dimensions are in mm. From: Lund et al. (2016).

from that of arch bridge superstructures, this choice of test procedure needs to be justified. The frost heave tests were performed in accordance with the ASTM D5918-13 standard for two main reasons: firstly, the test procedure is the only well-known procedure to determine the frost susceptibility of soil materials; and, secondly, the test procedure can be considered a worst-case scenario which means that the frost susceptibility classification is conservative; thus, if a subbase gravel material used for fill in Pearl-Chain Bridges is classified as 'frost safe' based on the ASTM D5918-13 standard, frost heave of the fill material will not occur. However, if a gravel material classified as 'frost susceptible' is used as fill in arch bridges, the drainage properties of the bridge superstructure become even more important than otherwise because it needs to be ensured that a constant water table is entirely prevented. The very first Pearl-Chain Bridge constructed in Denmark in 2015 consisted of a main arch and two adjacent half-arches as seen in Figure 2 (Lund et al. 2016). For such bridge design a constant water table can occur over the two middle supports if the drainage of the superstructure is poor.

Furthermore, a bridge superstructure differs from pavement by being exposed to freezing from several sides; hence, the water source does not have to lie below the fill material but could also be caused by water fed from the bridge ends, for example.

In the present study, frost susceptibility is determined from frost heave tests of four gravel materials - two Danish sub-base gravels, a high fines content modified sub-base gravel, and a zero fines content modified sub-base gravel - in order to evaluate how exposed the gravel materials are to freezing and thawing. Furthermore, the results are compared with the Danish criterion for determination of frost susceptibility, and to Casagrande's and Schaible's frost criteria. Finally, the permeability of the gravel materials is also determined in order to understand the freeze-thaw behavior.

\section{Background}

Despite the arch being the optimal shape for road and railway bridges, it is rarely used, mainly because of the extensive use of scaffolding needed for constructing such bridges, and the subsequent closing of the underpassing road during the months-long construction period. The Pearl-Chain Bridge technology has reintroduced the arch primarily for road and railway bridges, and the road only needs to be closed for a night. This reduces traffic disturbance and carbon dioxide emissions, and minimizes the cost. Furthermore, the use of material is minimized due to the optimal arch shape.

Thus, Pearl-Chain Bridge technology is an innovative arch solution for road and railway bridges. The Pearl-Chain Bridge superstructure consists of a Pearl-Chain arch, a fill material, and a wearing course. Depending on the span of the bridge, a concrete top plate can be cast on top of the fill, below the wearing course. The Pearl-Chain arch is created from prefabricated Super-Light Decks (SL-Decks), which consist of lightweight concrete blocks and normal concrete (Hertz 2015; Hertz et al. 2014). Each SL-Deck is given a slight inclination at the ends, and has a duct cast through it longitudinally. Thereby, by collecting and post-tensioning several SL-Decks 
on a wire, like pearls on a string, an arch is formed from straight elements. To simplify the assembly, the Pearl-Chain arch is placed on its side; when the SL-Decks have been emplaced, self-compacting mortar joints are cast between the decks, after which the arch is post-tensioned (Lund et al. 2015). Next, the Pearl-Chain arch is tilted and put into place using a crane (Halding et al. 2015). The entire arch is constructed next to the road, and depending on the span and width of the bridge, it is possible to place the Pearl-Chain arch within a weekend. Pearl-Chain Bridges are mainly designed for spans of up to 30 meters. When the arch is placed, spandrel walls are installed, a filling material is laid out, and either a post-tensioned concrete top plate is cast or the wearing course is placed directly on the fill.

\section{Method}

\subsection{Materials}

The present study investigates four different types of gravel material, which can be classified as follows: two are sub-base gravel materials, the third is sub-base gravel mixed with fly ash to increase the fines content, and the fourth is sub-base gravel with no fines less than $0.125 \mathrm{~mm}$ in diameter. The sub-base gravels from Jutland in the western part of Denmark are typically graded as 0-8 mm, whereas those from Zealand in the eastern part of Denmark are 0-63 mm. This geographical dependence is due to the expanse of the ice cap during the last ice age. The difference means that if sub-base gravel is to be used as fill in Pearl-Chain Bridges, the gradation of the fill is expected to vary substantially depending on where in Denmark the bridge is constructed. Thus, the present study investigates sub-base gravel materials from Jutland, later denoted as gravel A1, and those from Zealand, later denoted as gravel B1. The third gravel material, later denoted as gravel A2, was created by increasing the fines content of the 0-8 mm sub-base gravel to $20 \%$ by mixing it with Danish fly ash of type B4, since the particle size distribution of fly ash indicates that fly ash is frost dangerous (see Figure 1). Type B4 fly ash has a loss on ignition less than 4 weight- $\%$ and contains a maximum of $10 \%$ reactive lime in agreement with the requirements given in the DS 450-1 standard (DS Standard 450-1 2012). The fly ash in specimens A2 can be considered inert since the portlandite content is zero, the duration of the frost test is short, and the frost test is carried out at relatively low temperatures; hence fly ash will not positively affect the strength of the specimens. Having a fines content of $20 \%$, Schaible's and Casagrande's frost criteria suggest that gravel A2 is susceptible to frost. The fourth gravel material, later denoted as gravel B2, was created by sieving off fines content less than $0.125 \mathrm{~mm}$ in diameter from the 0-63 $\mathrm{mm}$ sub-base gravel. During preparation of specimens $\mathrm{B} 1$ and $\mathrm{B} 2$, particles greater than $31.5 \mathrm{~mm}$ in diameter were removed to fit the test equipment; thus, in the following sections, the particle size distribution of B1 and B2 relates to $0-31.5 \mathrm{~mm}$ and $0.125-31.5 \mathrm{~mm}$, respectively.

\subsection{Determination of Particle Size Distribution}

A standard sieving analysis does not include analysis of the fines content of particles less than $63 \mu \mathrm{m}$ in diameter. In this study, therefore, the particle size distribution was carried out in two steps: a sieving analysis was used to determine the gradation curves for particle sizes greater than $63 \mu \mathrm{m}$ in diameter; and, since the laser diffraction method is applicable to particles as small as $0.1 \mu \mathrm{m}$ in diameter (DS Standard 13320 2009), a laser diffraction analysis was used to determine the gradation of the particles less than $63 \mu \mathrm{m}$ in diameter. The sieve analysis was carried out in accordance with the DS 933-1 standard (DS Standard 933-1 2004). The fines content left from the sieve analysis was analyzed by way of wet analysis, using the laser diffractometer. To check the reliability of the laser diffractometer, a test was also performed on pure fly ash, and gave reasonable results when compared with the fly ash data sheet. Five tests were run for each gravel 
material, and the mean values were used to represent the materials. The results were expressed with respect to the entire particle size distribution determined from the sieve analysis of the specific gravel material.

\subsection{Determination of Optimal Water Content}

The vibrating table method was used to determine the optimal water content, and the maximum dry density, for gravels A1, A2 and B1 as described in the DS 13286-5 standard (DS Standard 13286-5 2003). The applied method is similar to Method B in the ASTM D4253-16 standard (ASTM Standard D4253-16 2016). Three tests were performed for each gravel type, and the mean values were used in further tests. The optimal water content for gravel B2 was assumed to be similar to that of gravel B1.

\subsection{Freeze-Thaw Experiments}

With minor corrections, the freeze-thaw experiments were carried out in accordance with the ASTM D5918-13 standard (ASTM Standard D5918-13 2013). Each test can be divided into two steps: preparation of the specimen prior to the freeze-thaw exposure, and the freeze-thaw test itself.

\subsubsection{Specimen Preparation}

Firstly, the gravel was wetted until its water content was one percentage point less than the optimal water content corresponding to water saturation determined from the vibrating table test. This is because Danish road regulations recommend decreasing the water content by up to three percentage points during preparation (Sub-base of Sand and Gravel - Design Guide 2003).

Afterwards, the gravel was placed in a mold consisting of six acrylic rings with an internal diameter of $140 \mathrm{~mm}$, a wall thickness of $4 \mathrm{~mm}$, and a height of $25 \mathrm{~mm}$ stacked one on top of each other. The dimension of the mold was independent of the gradation of the tested gravel material because the ASTM D5918-13 standard (ASTM Standard D5918-13 2013) does not consider the soil gradation. Each acrylic ring had a split cut through it longitudinally, and a hole with a diameter of $3.2 \mathrm{~mm}$ drilled at mid-height opposite to the split. The acrylic rings were stacked, with the splits placed above each other, and duct tape was used to make the acrylic rings stay in place. The six acrylic rings were placed on top of a spacer disk with a diameter of $148 \mathrm{~mm}$ and a height of $6.4 \mathrm{~mm}$. A $3 \mathrm{~mm}$ thick butyl tube membrane with a diameter of $136 \mathrm{~mm}$ was placed inside the rings, and stretched outside the spacer disk to obtain a sealed closing at the bottom of the mold. The butyl membrane was fastened to the perimeter of the upper acrylic ring using duct tape. The acrylic mold was then placed in a steel mold with an internal diameter of 150 $\mathrm{mm}$, leaving space for the acrylic mold and the spacer disk to be placed inside it. The top of the acrylic mold was in level with the top of the steel mold. A steel collar was fastened to the top of the steel mold. The mass of gravel corresponding to the inside volume of the acrylic mold was weighed, and placed in the mold in five loads of equal heights, each load compacted by 56 blows with a rammer. The rammer consisted of a steel disk with a diameter of $124 \mathrm{~mm}$ and a mass of $2.9 \mathrm{~kg}$, fastened to a handle. Vibration was only used when compacting specimens B1 and B2 since these specimens were the most difficult to compact. After all the gravel material was in place, the collar was removed and the height of the material reaching over the top of the mold was measured. From this height, the actual volume of the material could be found, and thereby it was possible to determine the compaction degree, $\delta[\%]$, using the formula:

$$
\delta=\frac{\rho_{\mathrm{d}}}{\rho_{\mathrm{d}, \max }} \times 100 \%
$$


where $\rho_{\mathrm{d}}\left[\mathrm{kg} / \mathrm{m}^{3}\right]$ is the dry density of the compacted gravel material, and $\rho_{\mathrm{d}, \max }\left[\mathrm{kg} / \mathrm{m}^{3}\right]$ is the maximum dry density determined from, for example, the vibrating table method (Sub-base of Sand and Gravel - GWS 2003).

The porosity, $P[\%]$, of the material was determined using the formula:

$$
P=\left(1-\frac{\rho_{d}}{\rho_{s}}\right) \times 100 \%
$$

where $\rho_{d}\left[\mathrm{~kg} / \mathrm{m}^{3}\right]$ is the dry density of the compacted gravel material, $\rho_{s}=2630 \mathrm{~kg} / \mathrm{m}^{3}$ is the soil particle density, and $\rho_{s}=2300 \mathrm{~kg} / \mathrm{m}^{3}$ is the fly ash particle density. For gravel mixed with fly ash, the particle density is weighted according to the percentage of fly ash.

The upper part of the specimen was removed so that its top surface aligned with the top of the mold, and the acrylic mold and spacer disk were removed from the steel mold. To copy the most vulnerable field conditions, the specimen was saturated with water prior to the freeze-thaw test. The approach used to saturate the specimen deviated from the approach described in the ASTM D5918-13 standard (ASTM Standard D5918-13 2013), since it was performed by water absorption where the bottom of the specimen was placed in water reaching $50 \mathrm{~mm}$ up the sides of the specimen. The spacer disk was removed, and then a fine mesh of $73 \mu \mathrm{m}$ and a coarser mesh of $10 \mathrm{~mm}$ were placed below the specimen. The coarse mesh was fastened to the sides of the specimen using a hose clamp. The fine mesh prevented any material from being washed out. The specimen was allowed to absorb water for three days, since preliminary tests had shown that the mass of the specimens with all types of gravel remained constant after three days.

\subsubsection{Freeze-Thaw Test Equipment}

The equipment for the actual freeze-thaw test consisted of five main components: a base plate connected to a water supply, two temperature plate systems, a surcharge weight, temperature sensors, and a refrigerator.

The base plate was placed directly beneath the water-saturated specimen that was still contained in the acrylic mold. Its purpose was to continuously supply the specimen with water through a water inlet and outlet placed on opposite sides of the base plate. The water inlet was connected to an external Mariotte water supply through a plastic tube with a diameter of 10 $\mathrm{mm}$. The water supply, which consisted of a $508 \mathrm{~mm}$ long plastic tube with a diameter of $57 \mathrm{~mm}$, worked on the principle of using a so-called 'bubble tube', a $533 \mathrm{~mm}$ long glass tube with an internal diameter of $3 \mathrm{~mm}$. This bubble tube was passed through a vacuum-tight rubber bung inserted into the top of the plastic tube. By moving the bubble tube vertically, it was possible to adjust the water head of the entire setup. When water flowed out of the specimen, the water head stayed at the level of the bottom of the bubble tube, as long as the end of the tube that was connected to the water outlet of the base plate remained open and was placed at the same level as the bottom of the bubble tube. During the test, the water head was set $10 \mathrm{~mm}$ above the bottom of the specimen. The base plate had a diameter of $150 \mathrm{~mm}$ and a height of $38 \mathrm{~mm}$, and the top of the base plate consisted of a $10 \mathrm{~mm}$ high circular rim with a diameter of $138 \mathrm{~mm}$, designed to hold a plastic mesh that ensured water would always be present directly below the specimen. A much finer mesh of $73 \mu \mathrm{m}$ was placed on top of the relatively coarse $10 \mathrm{~mm}$ high plastic mesh. Figure 3 shows how the specimen was placed on top of the base plate in the test setup.

Temperature plates of aluminum were placed on top of the specimen and below the base plate, as seen in Figure 3. The top and bottom temperature plates were connected to separate temperature control circulating baths controlling their temperatures. The top plate contained a 1:1 glycol-water solution, and the bottom plate contained pure water. A $10 \mathrm{~mm}$ plastic tube was connected from the temperature bath to the inlet of the temperature plate through a flow- 


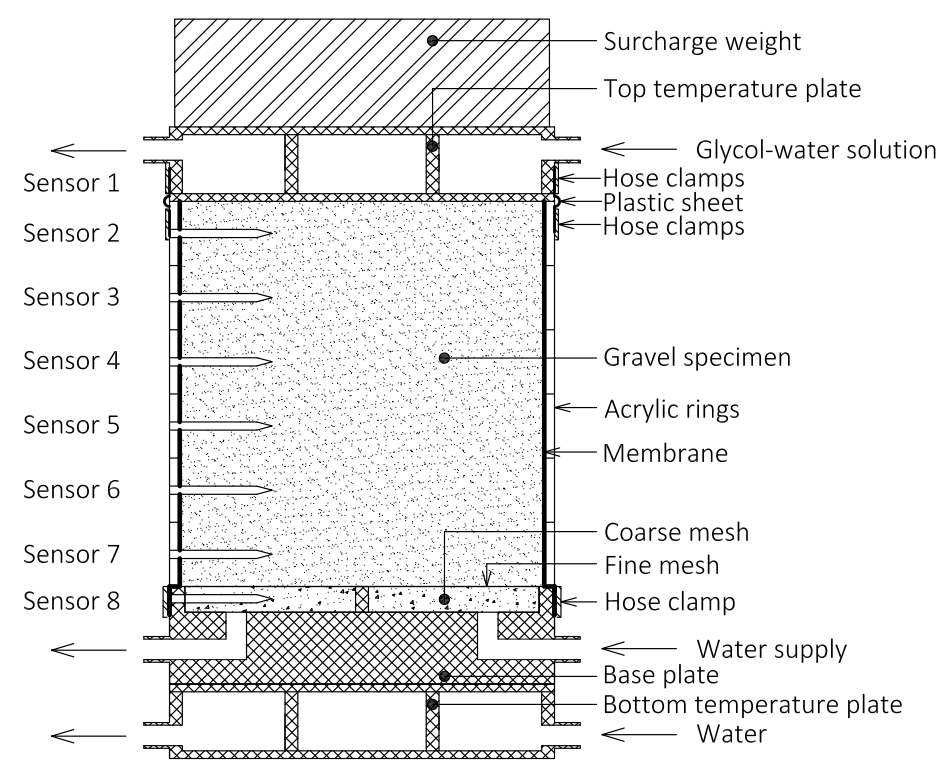

Figure 3. Principle sketch of the specimen setup for the freeze-thaw tests. Sensors 2 to 8 are placed in dip pipes, and sensor 1 is laid between the top temperature plate and the top of the specimen. Insulation is not shown.

meter, and a $10 \mathrm{~mm}$ plastic tube was connected from the outlet of the temperature plate to the temperature bath. The temperature plates had a diameter of $150 \mathrm{~mm}$ and an internal height of $24 \mathrm{~mm}$, and transverse walls ensured a water flow covering the entire surface. Before installing the top temperature plate, a small amount of silver iodide was placed on top of the specimen to initiate ice nucleation. During frost heaving, the top temperature plate would move upwards and leave a gap to the butyl membrane, exposing the specimen to the surroundings. To avoid any moisture loss, a plastic sheet cut from a plastic bag was fastened to the top temperature plate and to the acrylic mold using two hose clamps, allowing enough room for the specimen to expand vertically, as seen in Figure 3. The temperature settings for the two temperature baths are given in Table 1. As this shows, the temperature of the bottom plate remained positive, and only the temperature of the top plate became negative.

Table 1. Temperature variation of the two plates with time during the freeze-thaw test.

\begin{tabular}{|c|c|c|c|c|}
\hline Day & $\begin{array}{c}t \\
{[\mathrm{~h}]}\end{array}$ & $\begin{array}{c}T_{\text {top plate }} \\
\quad\left[{ }^{\circ} \mathrm{C}\right]\end{array}$ & $T_{\text {bot. plate }}$ & Comment \\
\hline 1 & 24 & 2.55 & 2.55 & Conditioning \\
\hline 2 & $\begin{array}{c}8 \\
16\end{array}$ & $\begin{array}{l}-3.45 \\
-12.45\end{array}$ & $\begin{array}{l}2.55 \\
0.50\end{array}$ & Freezing period \#1 \\
\hline 3 & $\begin{array}{c}16 \\
8\end{array}$ & $\begin{array}{l}11.55 \\
2.55\end{array}$ & $\begin{array}{l}2.55 \\
2.55\end{array}$ & $\begin{array}{l}\text { Thawing period \#1 } \\
\text { Stabilization }\end{array}$ \\
\hline 4 & $\begin{array}{c}8 \\
16\end{array}$ & $\begin{array}{l}-3.45 \\
-12.45\end{array}$ & $\begin{array}{l}2.55 \\
0.50\end{array}$ & Freezing period \#2 \\
\hline 5 & $\begin{array}{c}16 \\
8\end{array}$ & $\begin{array}{l}11.55 \\
2.55\end{array}$ & $\begin{array}{l}2.55 \\
3.00\end{array}$ & $\begin{array}{l}\text { Thawing period \#2 } \\
\text { Stabilization }\end{array}$ \\
\hline
\end{tabular}

$T_{\text {top plate }}=$ temperature of top plate $\left[{ }^{\circ} \mathrm{C}\right], T_{\text {bot. plate }}=$ temperature of bottom plate $\left[{ }^{\circ} \mathrm{C}\right], t=$ time $[\mathrm{h}]$

The freezing point depression was determined by compacting $20 \mathrm{~mm}$ gravel to maximum density in a $30 \mathrm{~mm}$ diameter test tube, and placing a pinch of silver iodide on top of it. A temperature 
sensor was placed in the middle of the compacted specimen, and the test tube was conditioned in a $0^{\circ} \mathrm{C}$ glycol-water bath. Subsequently, it was placed in a $-3^{\circ} \mathrm{C}$ liquid ethylene glycol bath, and its temperature variation was logged. The freezing point depression was determined as the temperature after nucleation, and for all types of gravel it was approximately $-0.45^{\circ} \mathrm{C}$. The temperatures in Table 1 are based on the temperatures given in the ASTM D5918-13 standard (ASTM Standard D5918-13 2013), corrected with respect to the freezing point depression. Moreover, the minimum temperature of the bottom temperature plate was changed from the recommended $0^{\circ} \mathrm{C}$ in the ASTM D5918-13 standard (ASTM Standard D5918-13 2013) to $0.5^{\circ} \mathrm{C}$, because the thermostat's temperature band around the set point otherwise caused the temperature of the bottom plate to drop below $0^{\circ} \mathrm{C}$. This would have caused the water below the specimen to freeze and cause an erroneous heave of the specimen. This was assumed not to influence the results because of two main reasons: (1) It was measured that the temperature of the bottom plate in fact varied between $0.04-0.5^{\circ} \mathrm{C}$ during the 16 -hour freezing period. These temperature measurements were calibrated against a certified mercury thermometer. Thus, the deviation from the recommended $0^{\circ} \mathrm{C}$ was considered to be minor. (2) As it will be clear from the following sections, the frost susceptibility classification relates to the 8-hour freezing period in which the temperature of the bottom plate was $2.55^{\circ} \mathrm{C}$ in accordance with the ASTM D5918-13 standard.

As seen in Table 1, the specimens were exposed to two identical frost cycles after an initial 24-hour conditioning period. Each frost cycle consisted of a 24-hour freezing period where the temperature of the top plate was decreased in two steps, followed by a 16-hour thawing period, and finally an 8-hour stabilization period bringing the temperature back to the original.

The surcharge steel weight of mass $5.5 \mathrm{~kg}$, with an outside diameter of $142 \mathrm{~mm}$ and a height of $42 \mathrm{~mm}$, was placed above the top temperature plate. A deformation gauge was installed on top of the surcharge weight to measure vertical displacement with an accuracy of $\pm 0.004 \mathrm{~mm}$.

A temperature sensor was inserted in the specimen through a hole drilled through each acrylic ring. Another temperature sensor was placed at the very top of the specimen, between the upper acrylic ring and the top temperature plate, and a third temperature sensor was placed below the specimen in a dip pipe inserted in the base plate. The temperature sensors inserted through the acrylic rings were also installed in dip pipes to ease the insertion, and to protect the heat-shrinkage tubing of the copper-constantan wires. Each dip pipe was $40 \mathrm{~mm}$ long, and had a diameter of $3.2 \mathrm{~mm}$. Other temperature sensors were placed in the refrigerator and in the two temperature baths. The temperature sensors had an accuracy of $\pm 0.1^{\circ} \mathrm{C}$.

The refrigerator was set to a constant temperature of $2^{\circ} \mathrm{C}$, but the temperature was varying between $-4^{\circ} \mathrm{C}$ and $8^{\circ} \mathrm{C}$. Holes were drilled in the sides of the refrigerator to accommodate the tubes connecting the temperature baths and the temperature plates, and for the tubes supplying and draining the system of water. After connecting the entire setup around the specimen, it was covered in $25 \mathrm{~mm}$ thick insulation to prevent any condensation. All plastic tubes inside and outside the refrigerator were covered as well as the specimen itself. The setup was placed on an insulation plate of extruded thermoplastic foam. All types of insulation had a thermal conductivity of $0.04 \mathrm{~W} /(\mathrm{m} \cdot \mathrm{K})$. Figure 4 shows the setup installed in the refrigerator.

A principle sketch of the entire freeze-thaw test setup is shown in Figure 5.

In total, two different specimens were tested for each gravel material, except for gravel B2 where only one specimen was tested.

\subsection{Permeability Test Setup}

The permeability of gravels A1, B1 and B2 was determined from a constant-head setup, and the permeability of gravel A2 was determined from a falling-head setup. Both setups are based on 


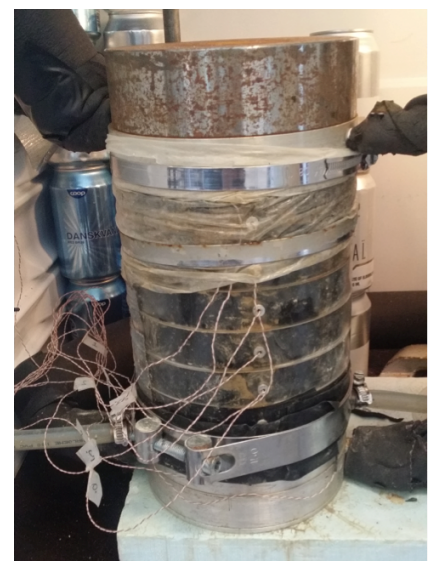

(a) Test setup without insulation.

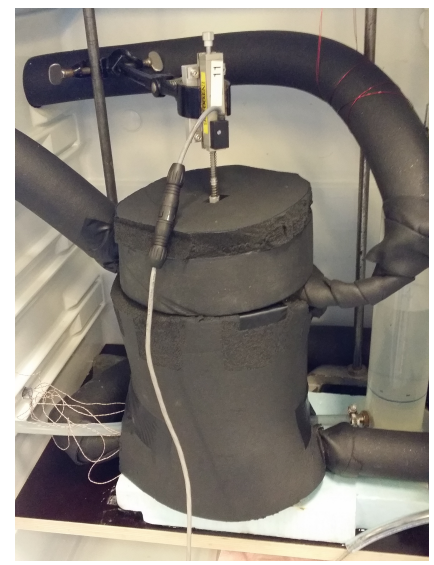

(b) Test setup covered in insulation to avoid condensation.

Figure 4. Freeze-thaw test setup in the refrigerator.

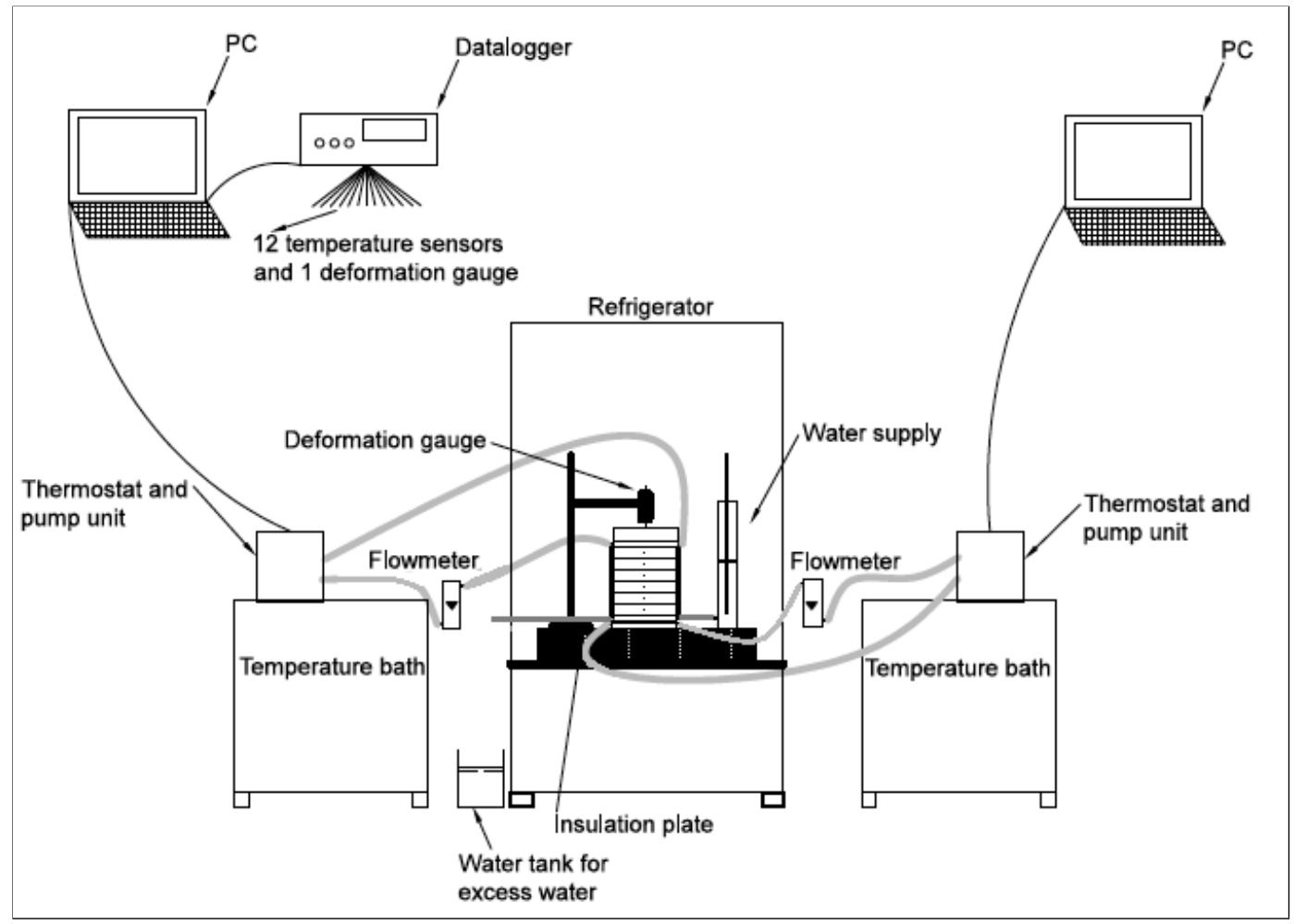

Figure 5. Principle sketch of entire freeze-thaw test setup. Insulation is not shown.

Darcy's law stating proportionality between flow velocity and hydraulic gradient. The constanthead setup that is most suitable for soils with a medium to high permeability was based on the ASTM D2434-68 standard (ASTM Standard D2434-68 2006), where a constant water head, $h[\mathrm{~m}]$, is established on top of a specimen with length $L[\mathrm{~m}]$ and cross-sectional area $A\left[\mathrm{~m}^{2}\right]$. The water volume, $Q\left[\mathrm{~m}^{3}\right]$, penetrating the specimen during time $t[\mathrm{~s}]$ is used to calculate the permeability coefficient at $20^{\circ} \mathrm{C}, k_{20}[\mathrm{~m} / \mathrm{s}]$, using the formula:

$$
k_{20}=\frac{Q L}{A h t} \frac{\eta_{T}}{\eta_{20}}
$$




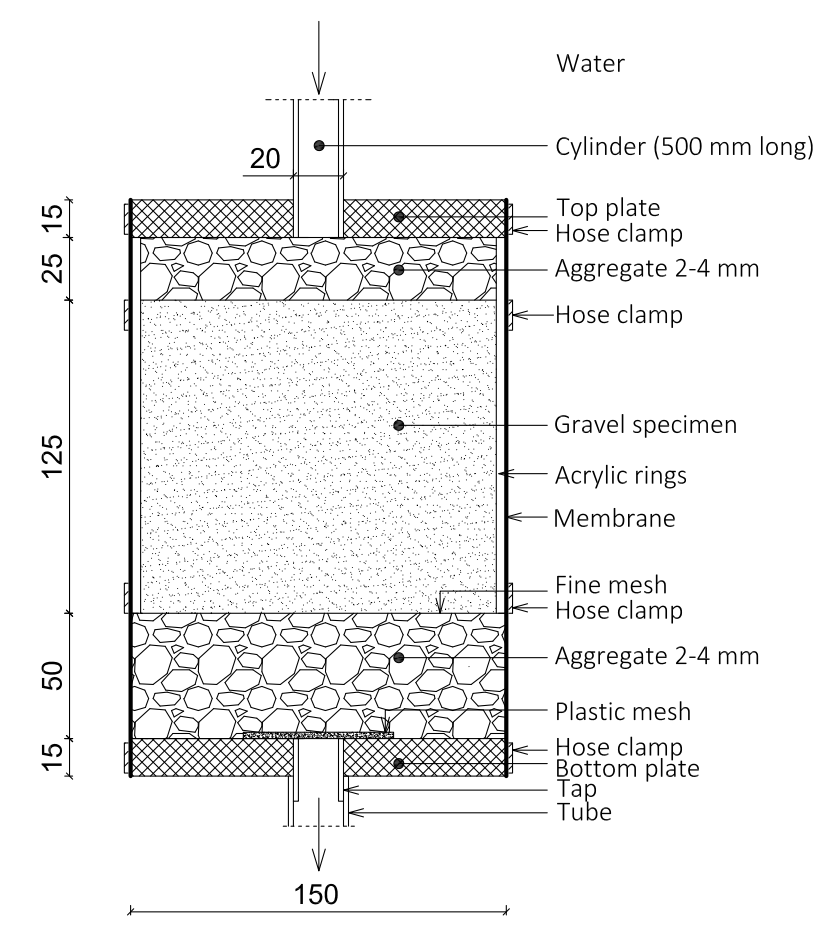

Figure 6. Constant- and falling-head permeability setup. Dimensions are in $\mathrm{mm}$.

where $\eta_{T}[\mathrm{~Pa} \cdot \mathrm{s}]$ is the water viscosity at the temperature, $T\left[{ }^{\circ} \mathrm{C}\right]$, at which the test is conducted, and $\eta_{20}[\mathrm{~Pa} \cdot \mathrm{s}]$ is the water viscosity at $20^{\circ} \mathrm{C}$.

The falling-head setup is most suitable for soils with a low permeability. The time difference, $t[\mathrm{~s}]$, between the initial and final water head difference, $h_{1}-h_{2}[\mathrm{~m}]$, is used to determine the permeability coefficient at $20^{\circ} \mathrm{C}, k_{20}[\mathrm{~m} / \mathrm{s}]$, using the formula:

$$
k_{20}=2.303 \frac{a L}{A t} \log _{10} \frac{h_{1}}{h_{2}} \frac{\eta_{T}}{\eta_{20}}
$$

where $a\left[\mathrm{~m}^{2}\right]$ is the cross-sectional area of the standpipe, $A\left[\mathrm{~m}^{2}\right]$ is the cross-sectional area of the specimen, $L[\mathrm{~m}]$ is the length of the specimen, $\eta_{T}[\mathrm{~Pa} \cdot \mathrm{s}]$ is the water viscosity at the temperature, $T\left[{ }^{\circ} \mathrm{C}\right]$, at which the test is conducted, and $\eta_{20}[\mathrm{~Pa} \cdot \mathrm{s}]$ is the water viscosity at $20^{\circ} \mathrm{C}$.

The preparation of the specimen used for the constant and falling-head tests was the same, as shown in Figure 6.

Firstly, the specimen was compacted in a $150 \mathrm{~mm}$ high acrylic cylinder with a diameter of 142 $\mathrm{mm}$, in the same way as the specimens used in the freeze-thaw tests, except that the height of the specimen was reduced to $125 \mathrm{~mm}$. The inside of the cylinder had been painted with epoxy resin, and sprinkled with $0-2 \mathrm{~mm}$ sand to roughen the surface and prevent water from easily escaping along the specimen sides. A $3 \mathrm{~mm}$ rubber membrane with an inner diameter of $150 \mathrm{~mm}$ was pulled over an aluminum bottom plate, and closed tightly to it using a hose clamp. A $20 \mathrm{~mm}$ hole had been drilled at the center of the bottom plate, and this connected a plastic tube to a tap for water outlet. A plastic mesh was placed above the hole to prevent any material from being washed out. A $50 \mathrm{~mm}$ layer of 2-4 $\mathrm{mm}$ aggregate was laid on top of the aluminum base inside the rubber membrane, and compacted with a rammer to provide a firm and even surface. The gravel specimen contained in the acrylic cylinder was placed on top of the aggregate inside the rubber membrane, and hose clamps were used to tighten the rubber membrane and the acrylic cylinder 


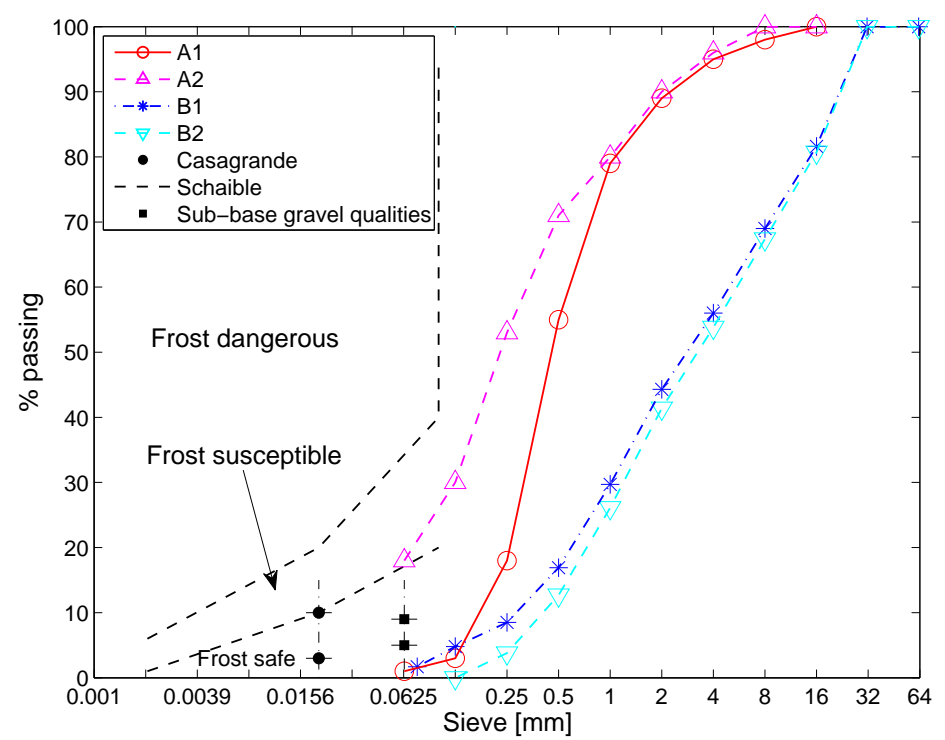

Figure 7. Gradation curves for gravels A1, A2, B1 and B2, together with Casagrande's and Schaible's frost criteria classifying whether a gravel material is frost safe, frost susceptible or frost dangerous. The gradation curves for gravels B1 and B2 are determined by removing particles greater than $31.5 \mathrm{~mm}$. The requirements for Danish quality I and quality II subbase gravel materials are also shown. Reference is made to Figure 1 for further explanation.

together. Another $25 \mathrm{~mm}$ layer of $2-4 \mathrm{~mm}$ aggregate was laid on top of the gravel specimen inside the acrylic cylinder, and compacted to provide a firm and even surface. The permeability of the $2-4 \mathrm{~mm}$ aggregate layer was $10.2 \mathrm{~cm} / \mathrm{s}$ as determined from a constant-head setup (Figure 6) using two water heads of $27 \mathrm{~cm}$ and $48 \mathrm{~cm}$, respectively, and a specimen height of $10 \mathrm{~cm}$. This permeability was considerably greater than that of the test materials and therefore did not influence the measurements. The setup was closed by placing an aluminum top plate on top of the aggregate, pulling the rubber membrane around it, and closing it tightly with a hose clamp. A $20 \mathrm{~mm}$ hole had been drilled in the top plate, and a $500 \mathrm{~mm}$ high plastic cylinder, with an inner diameter of $16 \mathrm{~mm}$ and a measurement scale along its height, was fastened to this hole to control and measure the water input.

In the constant-head setup, two water heads of $20 \mathrm{~cm}$ and $45 \mathrm{~cm}$, respectively, were each tested for gravels A1, B1 and B2. In the falling-head setup, the water head was varied between $60 \mathrm{~cm}$ down to $20 \mathrm{~cm}$ in steps of $5 \mathrm{~cm}$ for gravel A2. Three specimens were tested for each type of gravel.

\section{Results}

\subsection{Particle Size Distribution and Fines Content}

Figure 7 shows the particle size distributions for gravel particles greater than $63 \mu \mathrm{m}$ and less than $31.5 \mathrm{~mm}$ in diameter. Casagrande's and Schaible's frost criteria, and Danish definitions of sub-base gravel qualities I and II are also shown. Based solely on the gradation curves of gravels $\mathrm{A} 1, \mathrm{~B} 1$ and B2, they are seen to be classified as quality I materials.

The coefficient of uniformity $\left(C_{u}\right)$ is defined as the ratio between the particle diameters at $60 \%$ passing and at $10 \%$ passing. The $C_{u}$ s for gravels A1, A2, B1 and B2 were 6.0, 17.5, 16.7 and 12.5, respectively. From the sieve analysis, the fines contents were found to be $1.1 \%, 18.2 \%$ and $2.4 \%$ for gravels A1, A2 and B1, respectively. No fines content was present for gravel B2. The results from the laser diffractometer analysis are shown in Figure 8, where it is assumed 


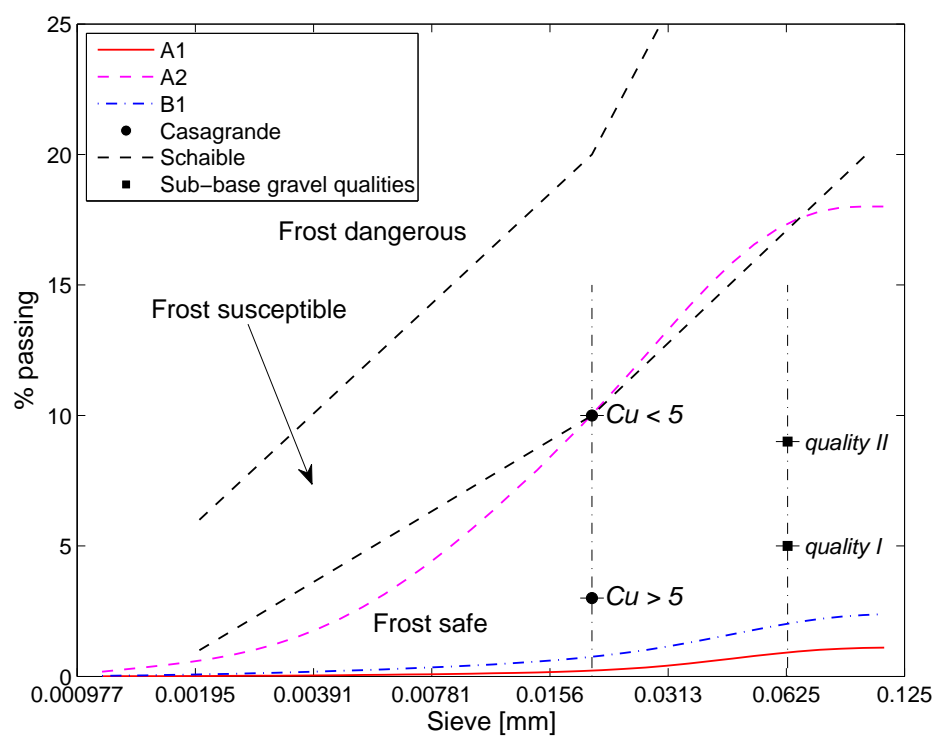

Figure 8. Fines content for gravels A1, A2 and B1 determined from laser diffraction. Gravel B2 does not have any fines content less than $0.125 \mathrm{~mm}$ in diameter. Casagrande's and Schaible's limit curves classifying whether a gravel material is frost safe, frost susceptible or frost dangerous are also shown, together with the requirements for Danish quality I and quality II sub-base gravel materials.

that the total percentage of fines analyzed for each gravel material corresponds to the measured fines content.

Figure 8 shows that gravels A1, B1 and B2 are expected to be frost safe based on both Casagrande's and Schaible's frost criteria. This is as expected because both materials comprise sub-base gravel of quality I (Sub-base of Sand and Gravel - Design Guide 2003), which requires the material to be frost safe. However, due to its high fines content, gravel A2 is frost-susceptible according to both frost criteria.

\subsection{Optimal Water Content and Maximum Dry Density}

Table 2 shows the maximum density and the optimal water content for all gravels analyzed. When preparing the specimens for the freeze-thaw tests, the compaction degree was calculated using equation (1) to be $99 \%$ for specimens A1, $100 \%$ for specimens A2, $97 \%$ for specimens B1, and $96 \%$ for specimen B2. In practice, it is very difficult to control that all specimens obtain the same degree of compaction; thus, it was intended to prepare all specimens with the highest possible degree of compaction. The results show that the variation in degrees of compaction is narrow and furthermore complies with the requirements given in Danish road regulations (Subbase of Sand and Gravel - GWS 2003); hence, the variation represents what is expected and allowed for sub-base gravel in the field, and the variation's influence on the results is therefore not considered any further since it is expected to be minimal.

\subsection{Freeze-Thaw Results}

In the following, the results from the freeze-thaw tests will be exemplified by means of specimen B1-1. However, the analysis presented has been carried out for all types of gravel, and the corresponding results are shown for all specimens. 


\subsubsection{Porosity of Freeze-Thaw Specimens}

The mean porosity of the specimens is shown in Table 2. Gravel A2, which has the highest fine contents, has the highest porosity. Even though gravels A1 and B1 have approximately the same fines content, their porosity is seen to differ. Gravel B1 has the lowest porosity.

\begin{tabular}{|c|c|c|c|c|c|}
\hline \multirow{2}{*}{$\begin{array}{l}\text { Specimen } \\
\text { no. }\end{array}$} & \multirow{2}{*}{$\begin{array}{c}\text { Porosity } \\
{[\%]}\end{array}$} & \multirow{2}{*}{$\begin{array}{l}\text { Max. density } \\
\quad\left[\mathrm{kg} / \mathrm{m}^{3}\right]\end{array}$} & \multicolumn{3}{|c|}{ Water content $[\%]$} \\
\hline & & & $w_{\text {opt }}$ & $w_{\text {act }}$ & $w_{\text {term }}$ \\
\hline A1-1 & 33.9 & 1911 & 12.8 & 11.9 & 15.4 \\
\hline $\mathrm{A} 1-2$ & 33.3 & 1911 & 12.8 & 11.9 & 13.0 \\
\hline A2-1 & 48.0 & 1417 & 11.1 & 10.1 & 10.0 \\
\hline A2-2 & 47.8 & 1417 & 11.1 & 10.1 & 9.9 \\
\hline B1-1 & 24.0 & 2171 & 7.9 & 7.1 & 7.2 \\
\hline B1-2 & 22.2 & 2171 & 7.9 & 7.1 & 7.1 \\
\hline B2-1 & 26.5 & $2171(*)$ & $7.9(*)$ & 7.4 & 7.3 \\
\hline
\end{tabular}

\subsubsection{Moisture Content of Freeze-Thaw Specimens}

Table 2 summarizes the mean moisture content of the specimens during preparation, and immediately after termination of the freeze-thaw tests where each specimen was divided into six parts by removing one acrylic ring at a time, together with the gravel contained within it. The moisture content was measured for each of the six portions, and thereby a moisture profile was obtained as shown in Figure 9.

For specimens A1 and B1, the moisture content no longer remained homogeneous after termination of the frost tests, but increased from top to bottom, as expected since water was supplied from below. The mean moisture content of specimens A1 increased compared with the water content at the time of preparation, possibly due to water being retained in the gravel after being transported to the freezing zone. For specimens A2, B1 and B2, the mean moisture content remained at the same level as during preparation; however, as seen in Figure 9(c), the moisture content at the top of B1-1 was $6.5 \%$ and the moisture content at the bottom was $9.0 \%$. Thus, compared with the optimal water content, the top of specimen B1-1 was no longer water-saturated, whereas the bottom was over-saturated. For specimens A2 and B2, the moisture content was homogeneous after termination of the frost tests, and the variation throughout the specimens was small.

\subsubsection{Temperature Profiles and Frost Penetration in Freeze-Thaw Specimens}

The temperature variation in the specimen was measured continuously at eight points during the freeze-thaw tests, and also in the temperature baths. Figure 10 shows this variation for specimen B1-1 during the five-day long test.

The temperature variations of the top and bottom temperature plates are seen to change stepwise, in agreement with the temperature limits given in Table 1. Figure 10 also shows that all temperatures within specimen B1-1 become negative during the freezing period, which means that the entire specimen freezes. However, the temperature of the bottom plate never reaches negative temperatures during the entire test, which means that the water supply does not freeze.

Figure 11 shows the frost penetration of specimen B1-1 with time, thereby illustrating the progress of the freezing front.

Figure 11 shows that it takes a little longer than half a day for the entire specimen to freeze. After the 8-hour freezing period - on which the frost heave rate is determined and the frost 


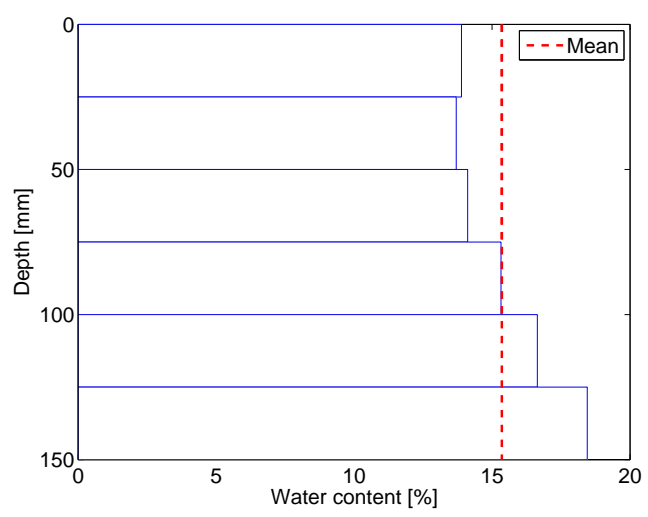

(a) A1-1.

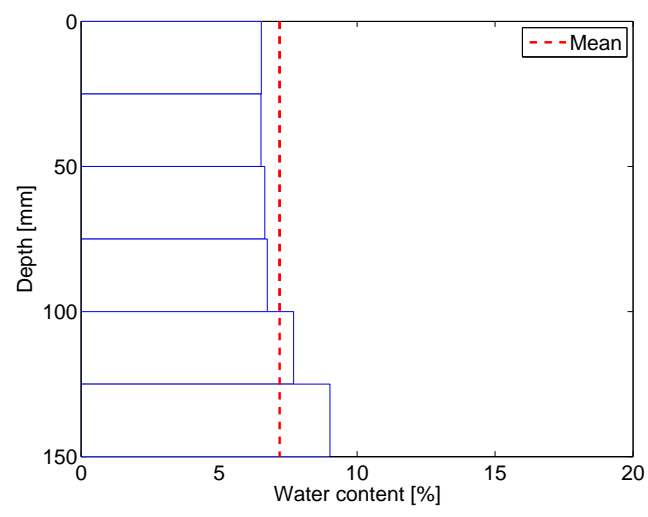

(c) B1-1.

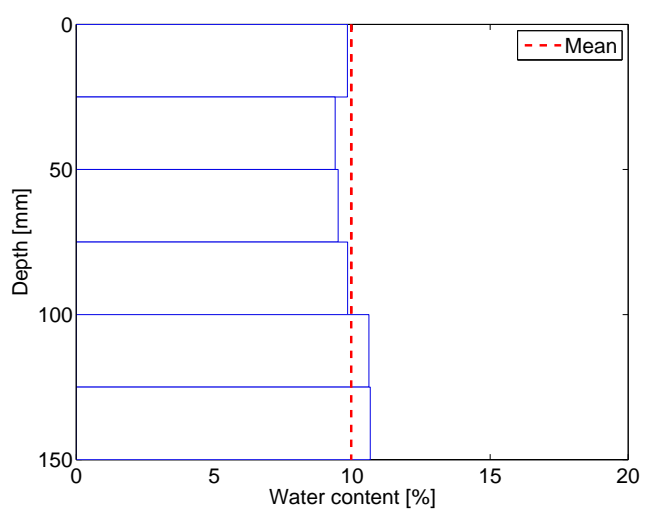

(b) A2-1.

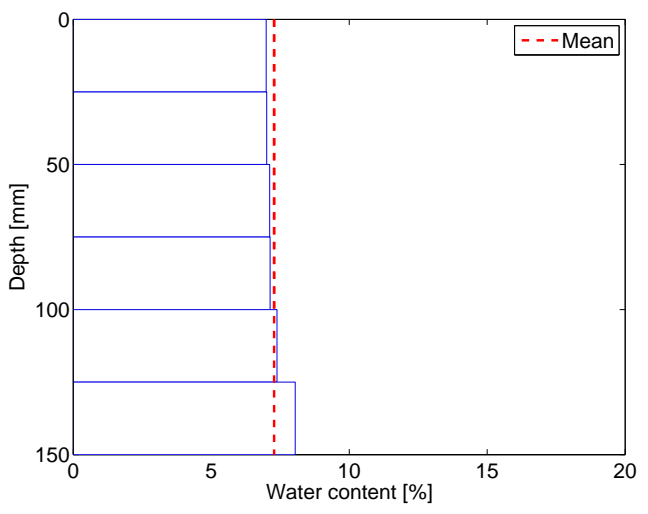

(d) B2-1.

Figure 9. Moisture profiles of specimens after termination of the frost tests. A depth of $0 \mathrm{~cm}$ corresponds to the top of the specimen where freezing takes place.

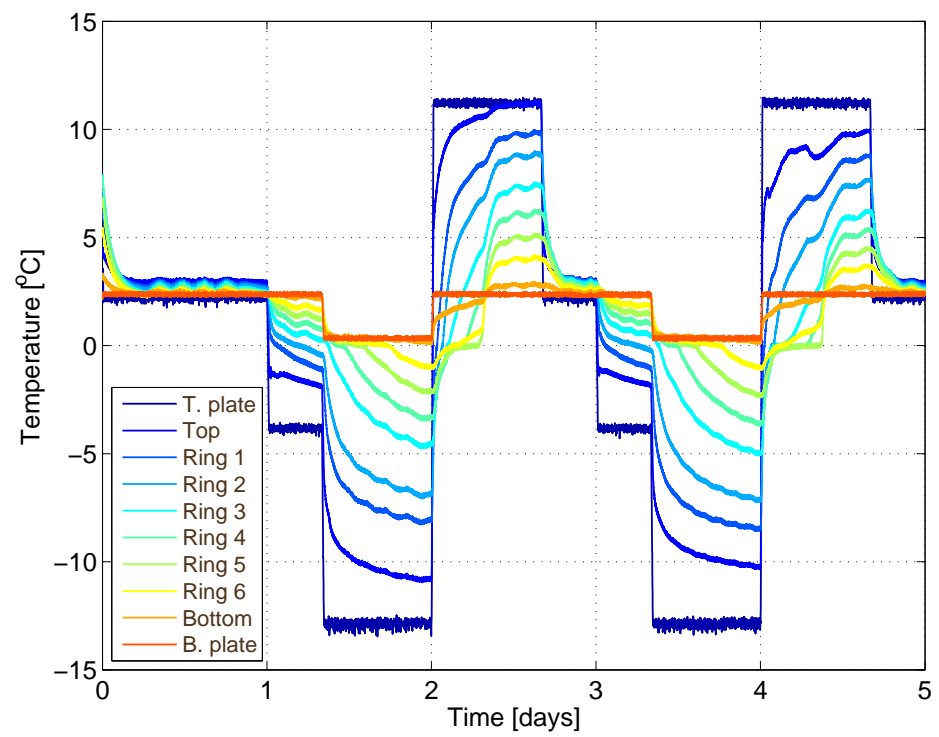

Figure 10. Temperature variations in specimen B1-1 during the freezethaw test. The temperature variations of the top $(\mathrm{T})$ plate and the bottom (B) plate are also shown. 


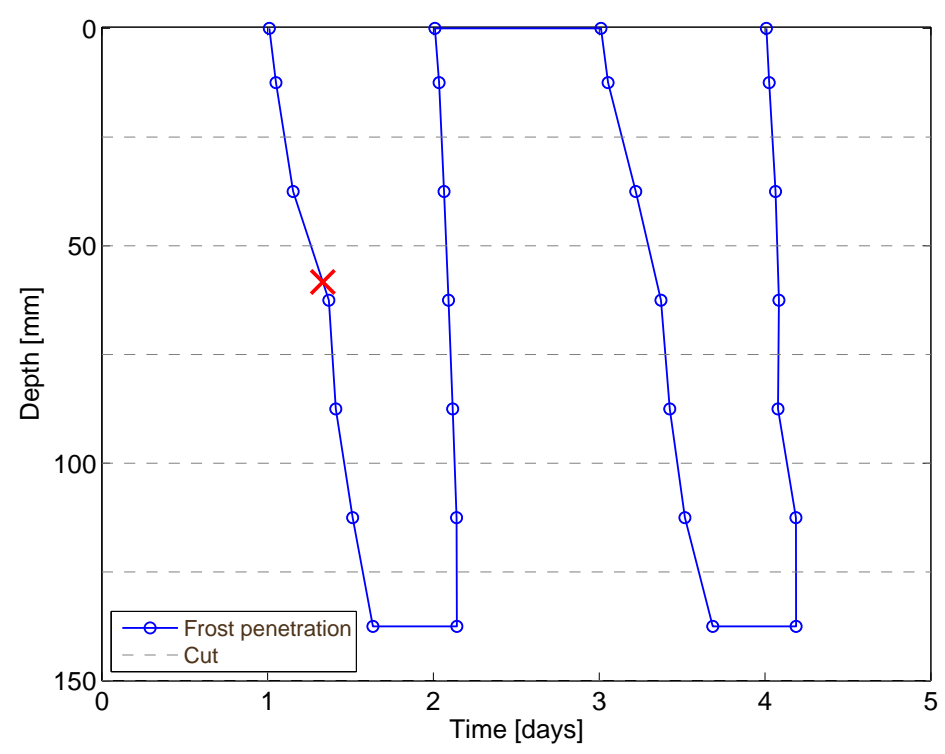

Figure 11. Frost penetration in specimen B1-1 during freezing and thawing. A depth of $0 \mathrm{~cm}$ corresponds to the top of the specimen where freezing takes place. The ' $\times$ ' marks the depth of the frost penetration $(58 \mathrm{~mm})$ after the first 8-hour freezing period.

susceptibility is assessed - the freezing front has reached less than halfway down the specimen. The entire specimen stays frozen for half a day, after which it is thawed. It only takes two hours for the specimen to thaw because thawing is induced from top and bottom. The specimen stays thawed for 24 hours before the second frost cycle is initiated, and the same trends are observed for the second frost cycle as for the first.

\subsubsection{Heave Rate, Frost Susceptibility and Deformation of Freeze-Thaw Specimens}

Figure 12 shows the vertical deformation of specimen B1-1 with time during the five-days freezethaw test. Two freezing periods can be clearly discerned by the two deformation peaks.

Figure 12 shows how the specimen starts to heave during the first frost cycle until thawing is initiated, after which some of the deformation is reversed. However, a permanent deformation of approximately $1 \mathrm{~mm}$ occurs during the first thawing period. A similar pattern emerges for the second freeze-thaw period, with a permanent deformation of approximately $2.5 \mathrm{~mm}$. According to the ASTM D5918-13 standard (ASTM Standard D5918-13 2013), the frost susceptibility is assessed by determining the 8-hour heave rates.

During the first and second freezing period, the deformation of the specimen is a combination of (1) expansion of the pore water during phase change from liquid to solid state, and (2) formation of ice lenses due to water migration to the frozen fringe. For specimen B1-1, Figure 11 shows that after the first 8-hour freezing period, the freezing front has reached $58 \mathrm{~mm}$ down through the specimen measured from the top of the specimen. According to Table 2 the porosity of specimen B1-1 is $24 \%$, which means that the deformation caused by pore water freezing and expanding $9 \%$ is approximately $1.3 \mathrm{~mm}$, if assuming that the specimen is water-saturated. This deformation is less than the total deformation of $2.1 \mathrm{~mm}$ measured after the first 8-hour freezing period (see Figure 12); thus, frost heave does occur during the first 8-hour freezing period. This also means that the 8-hour heave rate is based on a deformation caused by a combination of frost heave and pore water that freezes and expands, and according to the ASTM D5918-13 standard the frost susceptibility classification is based on this 8-hour heave rate even though it is not solely related to the 'true' frost heave rate. The same is true for specimen B1-2, and for specimens A2. For specimens A1 and B2, the deformation after the 8-hour freezing period is primarily caused by the expansion of the pore water which, as seen from the following paragraphs, also influences 


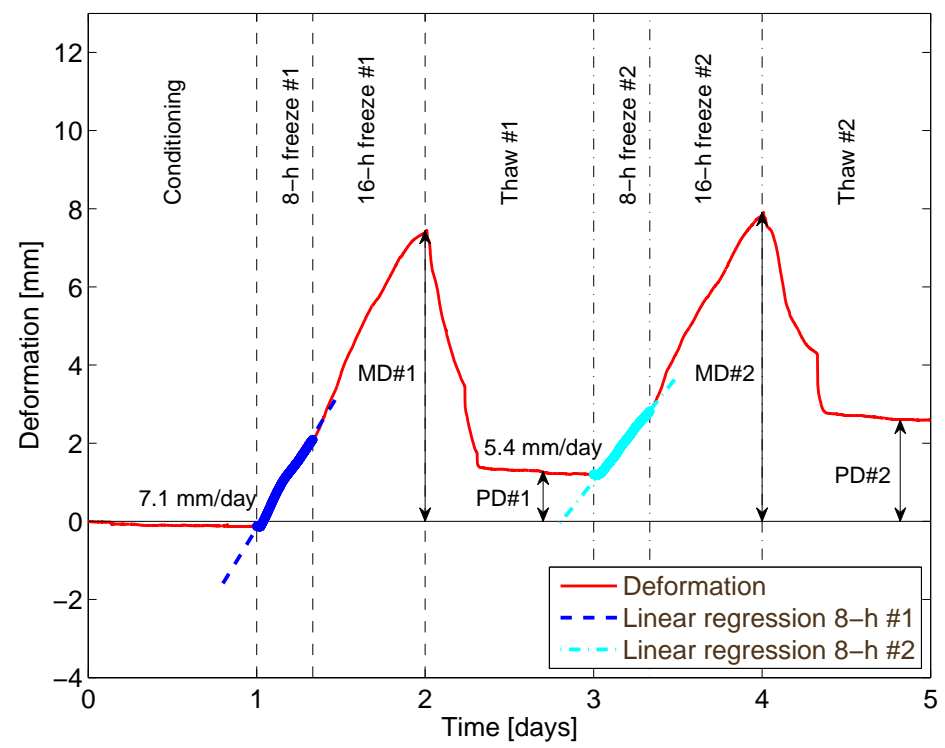

Figure 12. Vertical deformation of specimen B1-1 with time. The heave rate per day has been calculated as a linear regression of the data points during the 8-hour freezing period for frost cycles \#1 and \#2. The location of maximum deformations (MD) and permanent deformations (PD) are also shown.

Table 3. 8-hour heave rate during frost cycles \#1 and \#2, and frost susceptibility classifications for gravels A1, A2, B1 and B2.

\begin{tabular}{l|ccc}
\hline $\begin{array}{l}\text { Specimen } \\
\text { no. }\end{array}$ & $\begin{array}{c}\text { Heave rate \#1 } \\
{[\mathrm{mm} / \text { day }]}\end{array}$ & $\begin{array}{c}\text { Heave rate \#2 } \\
{[\mathrm{mm} / \text { day }]}\end{array}$ & $\begin{array}{c}\text { Frost susceptibility } \\
\text { classification }\end{array}$ \\
\hline A1-1 & 1.4 & 0.3 & $\begin{array}{c}\text { Negligible } \\
\text { A1-2 }\end{array}$ \\
0.8 & 0.4 & Negligible \\
\hline A2-1 & 4.7 & 3.6 & Low \\
A2-2 & 7.0 & 5.3 & Medium \\
\hline B1-1 & 7.1 & 5.4 & Medium \\
B1-2 & 6.9 & 4.1 & Medium \\
\hline B2-1 & 5.4 & 3.5 & Low \\
\hline
\end{tabular}

the frost susceptibility classification that is less critical for specimens A1 and B2.

The 8-hour heave rates are determined from a linear regression of all data points in the 8hour heave periods. In Figure 12, this gives heave rates of $7.1 \mathrm{~mm} /$ day for the first freezing period, and $5.4 \mathrm{~mm} /$ day for the second freezing period. In climates where many annual frost cycles take place, such as Denmark's, the second heave rate should be used to evaluate the frost susceptibility. This classifies the frost susceptibility of the material as 'medium' on a frost susceptibility scale with classifications: 'negligible', 'very low', 'low', 'medium', 'high' and 'very high'. Table 3 summarizes the heave rates and the frost susceptibility classifications.

Table 3 shows that the frost susceptibility is 'negligible' for sub-base gravel A1, but 'medium' for sub-base gravel B1. Gravel A2, with increased fines content, has 'low' to 'medium' frost susceptibility, and gravel B2 with decreased fines content has 'low' frost susceptibility.

The maximum and permanent deformations obtained after the first and second frost cycles are shown in Table 4 . The permanent deformations are measured during the thaw periods when the specimens are known to be completely thawed.

Table 4 shows that the maximum deformation of specimen B1 is about double the amount of that of specimens A2, and more than five times greater than that of specimens A1. For specimens A1, no permanent deformation is observed. For specimens A2, a small permanent deformation is observed after the second frost cycle. For specimens B1, a permanent deformation of up 
Table 4. Maximum vertical deformation (MD) during freezing and thawing in frost cycles \#1 and \#2, and permanent vertical deformation (PD) after frost cycles \#1 and \#2. All specimens were $150 \mathrm{~mm}$ high. $\left(^{*}\right)$ The maximum and permanent deformation during frost cycle \#1 are not found due to PC breakdown.

\begin{tabular}{l|cc|cc}
\hline & \multicolumn{3}{|c}{ Maximum def. [mm] } & Permanent def. [mm] \\
\hline Specimen no. & MD\#1 & MD\#2 & PD\#1 & PD\#2 \\
\hline A1-1 & 0.7 & 0.4 & 0.1 & -0.1 \\
A1-2 & 0.8 & 1.0 & -0.4 & -0.6 \\
\hline A2-1 & 2.8 & 2.5 & 0.0 & 0.3 \\
A2-2 & 4.2 & 2.6 & -0.1 & 0.7 \\
\hline B1-1 & 6.3 & 5.4 & 1.1 & 2.5 \\
B1-2 & 5.7 & 5.2 & 0.7 & 1.6 \\
\hline B2-1 & $(*)$ & 4.0 & $(*)$ & 0.8 \\
\hline
\end{tabular}

Table 5. Permeability coefficient, $k_{20}$, of gravels A1, A2, B1 and B2.

\begin{tabular}{l|cccc}
\hline$k_{20}[\mathrm{~cm} / \mathrm{s}]$ & $\mathrm{A} 1$ & $\mathrm{~A} 2$ & $\mathrm{~B} 1$ & $\mathrm{~B} 2$ \\
\hline Mean & $7.3 \times 10^{-4}$ & $0.65 \times 10^{-4}$ & $35 \times 10^{-4}$ & $37 \times 10^{-4}$ \\
Std. dev. & $1.4 \times 10^{-4}$ & $0.0035 \times 10^{-4}$ & $12 \times 10^{-4}$ & $6.1 \times 10^{-4}$ \\
\hline
\end{tabular}

to $2.5 \mathrm{~mm}$ is observed. Specimen B2 experiences the second largest maximum and permanent deformations of all four types of gravel.

\subsection{Permeability Results}

Table 5 shows the mean permeability coefficients for gravels A1, A2, B1 and B2, and the standard deviations.

Increasing the fines content of gravel A1 from $1.1 \%$ to $20 \%$ reduces the permeability coefficient by a factor of 10; hence gravel A2 has the lowest permeability coefficient. On the other hand, gravel B2 with the lowest fines content has the highest permeability coefficient.

\section{Discussion}

\subsection{Discussion of Frost Susceptibility of Sub-base Gravels}

The two gravel materials sensitive to frost heave in the present study had fines contents of $18.2 \%$ and $2.4 \%$, respectively; counterintuitively, the gravel material with $2.4 \%$ fines was found to be more frost-susceptible than the gravel material with $18.2 \%$ fines. The gravel material with $2.4 \%$ fines was classified as Danish sub-base gravel of quality I, and such a material experiencing frost heaving was surprising and unexpected.

The results from the present study suggest that the criterion used to classify the frost susceptibility of Danish sub-base gravel materials solely from their fines content is insufficient, and that the permeability coefficient should also be considered. Moreover, the results suggest that the deformation during the freeze-thaw period is directly related to the classification of the frost susceptibility in the ASTM D5918-13 standard (ASTM Standard D5918-13 2013).

\subsubsection{Influence of the Fines Content}

According to the frost heave tests, the frost susceptibility of gravel A1 was classified as 'negligible' indicating that no problems with frost heaving were expected. This was in line with the fines content analysis, with Casagrande's and Schaible's frost criteria, and with the classification of the material as a sub-base gravel of quality I. According to the frost heave tests, the frost 
susceptibility of gravel A2 was classified as 'low' to 'medium', indicating that a certain frost heaving was expected to take place. The fines content of gravel A2 was considerably higher than that of gravels A1, B1 and B2, and according to Casagrande's and Schaible's frost criteria it was expected that the material would be frost-susceptible. According to the frost heave tests, the frost susceptibility of gravel B1 was classified as 'medium', indicating that frost heaving was expected to take place. From the analysis of fines content, and Casagrande's and Schaible's frost criteria, it was not expected that any specific frost heaving would occur. When removing all fines less than $0.125 \mathrm{~mm}$ in diameter from gravel B1, the frost susceptibility decreased, and the frost susceptibility of gravel B2 was classified as 'low'. Hence, the frost susceptibility of gravel A2 and that of gravel B1 were minimized by decreasing the fines content of the materials.

\subsubsection{Influence of the Permeability Coefficient}

The permeability coefficients shown in Table 5 represent the minimum permeability coefficients for the different gravel materials, since they are determined for specimens having the optimal water content (Lambe and Whitman 1969). The permeability coefficients range according to the order of the particle size distributions, with gravel A2 having the smallest permeability coefficient and gravel B2 having the largest.

The permeability coefficient for gravel B1 is almost five times as big as the permeability coefficient for gravel $\mathrm{A} 1$, and gravel $\mathrm{B} 1$ has a $C_{u}$ three times greater than gravel $\mathrm{A} 1$. It is, therefore, expected that gravel B1 should pack better than gravel A1, which is also clear from Table 2 where the porosity of gravel B1 is seen to be lower than that of gravel A1. On the other hand, the pores of gravel B1 are larger than the pores of gravel A1 because gravel B1 is coarser than gravel A1, and the tortuosity of the pore system of gravel B1 is therefore less than that of gravel A1, which means that water is more easily transported through the material for B1. As a result, the permeability coefficient of gravel B1 is greater than of gravel A1. The difference in gradation suggests that even though the fines content of the two materials is approximately the same, it is easier for water to migrate towards the freezing zone in specimens B1 than it is in specimens A1; hence, the formation of ice lenses is more favorable for specimens B1 than for specimens A1. The same analogy can be used when comparing specimens A1 and B2.

The permeability coefficient for gravel A2 is almost 10 times less than that of gravel A1 despite the porosity of gravel A2 being the largest for the four gravel materials. However, because the fines content of gravel A2 is high, the pore system of specimens A2 is fine and the tortuosity of the pore system is thereby large, resulting in a small permeability coefficient. This small permeability coefficient is also believed to explain why the moisture profiles obtained from specimens A2 remained homogeneous after termination of frost tests.

\subsubsection{Influence of Deformation during the Freeze-Thaw Cycle}

A permanent deformation takes place for specimens A2, B1 and B2 (see Table 4), which are all classified as having 'low' or 'medium' frost susceptibility. The more frost-susceptible the specimens are, the more vulnerable they are to permanent deformations. Specimens A1 do not experience any permanent deformation, and are classified as having 'negligible' frost susceptibility.

Gravel B1 was found to experience the largest maximum vertical deformation. The vertical deformations of specimens B1 did not reach a constant level when initiating the thaw period for any of the two frost cycles, as can be seen in Figure 12. However, specimens A1, A2 and B2 all reached a constant vertical deformation before initiating the thaw periods. When comparing specimens A1 and A2 and specimens B1 and B2, Table 4 shows that not only does the heave rate increase, but the permanent and maximum deformations also increase when the fines content of the material is increased.

Even though the deformation itself is not used as a criterion for assessing whether or not a soil material is frost-susceptible according to the ASTM D5918-13 standard (ASTM Standard 
D5918-13 2013), the results suggest that the maximum and permanent deformations are directly related to the frost susceptibility classification.

\subsection{Validity of Freeze-Thaw Test Results for Pearl-Chain Bridges}

The freeze-thaw tests carried out in the present study attempt to experimentally identify potential freeze-thaw problems with sub-base gravel used as fill in Pearl-Chain Bridges. The ASTM D5918-13 standard (ASTM Standard D5918-13 2013) used in the planning of the tests is developed for the classification of frost susceptibility of soils used in pavements. It has already been justified why this standard was used (Section 1) so this section only concerns the simplicity of the applied testing procedure. The test in the present study was one-dimensional since freezing was only applied from one end. However, when used as fill in Pearl-Chain Bridges, the sub-base gravel is exposed to a three-dimensional freezing: from underneath the bridge, from above the bridge and from the sides; hence there will be more than a single freezing front. This condition cannot be adopted in the present testing procedure because it would cause the water feed to freeze, and change the imitation of ice lens growth caused by continuous water addition from underneath a freezing line in the soil. The continuous water feed adopted in the present study can be considered a worst-case scenario. The use of the testing procedure described in the ASTM D5918-13 standard (ASTM Standard D5918-13 2013) is chosen because it provides a reasonable system that makes it possible to classify and compare the frost susceptibility of different gravel materials. Also, when modeling the frost heave of gravel fill in Pearl-Chain Bridges, the analysis would most likely be one-dimensional and not three-dimensional.

\section{Conclusions}

In the present study, the frost susceptibility of two Danish sub-base gravel materials with fewer than $3 \%$ particles less than $63 \mu \mathrm{m}$ in diameter has been experimentally tested in a freeze-thaw test setup based on the ASTM D5918-13 standard (ASTM Standard D5918-13 2013). Two modified sub-base gravel materials have also been tested; one $0-8 \mathrm{~mm}$ sub-base gravel material having the fines content increased to $20 \%$ by use of fly ash, and one $0-63 \mathrm{~mm}$ sub-base gravel material with all particles less than $0.125 \mathrm{~mm}$ in diameter having been removed. Particles greater than $31.5 \mathrm{~mm}$ were removed from all materials to fit the test equipment. The heave rate was used to classify the frost susceptibility of the four gravel materials. Moreover, their permeability was determined. The main conclusions from the study can be summarized as follows:

(1) A water-saturated sub-base gravel material with a gradation of $0-8 \mathrm{~mm}$ and a fines content of $1.1 \%$ was found to have 'negligible' frost susceptibility. A water-saturated modified subbase gravel material with a gradation of $0-8 \mathrm{~mm}$ and a fines content of $20 \%$ - increased from the original $1.1 \%$ by the addition of fly ash - was found to have 'low' to 'medium' frost susceptibility. A water-saturated sub-base gravel material with a gradation of $0-31.5$ $\mathrm{mm}$ and a fines content of $2.4 \%$ was found to have 'medium' frost susceptibility. A watersaturated modified sub-base gravel material with a gradation of $0.125-31.5 \mathrm{~mm}$ was found to have 'low' frost susceptibility. According to Casagrande's and Schaible's frost criteria, only the gravel material with increased fines content was expected to experience frost heaving. It was not expected that any frost heaving would occur for sub-base gravel.

(2) The permeability coefficient of $0-31.5 \mathrm{~mm}$ sub-base gravel was five times greater than the permeability coefficient of $0-8 \mathrm{~mm}$ sub-base gravel due to the pore system being coarser, and the tortuosity of the pore system being less. Hence, it was easier for water to reach the freezing zone in $0-31.5 \mathrm{~mm}$ sub-base gravel.

(3) The permanent and maximum deformations, that occurred during the freeze-thaw cycle, were directly related to the frost susceptibility classification. 
(4) The results from the present study suggest that the criterion used to classify the frost susceptibility of Danish sub-base gravel materials solely from their fines content is insufficient, and that the permeability coefficient should also be considered. This is because the fines content of both sub-base gravel materials tested in the present study was low and the main difference was their permeability; thus, the permeability is believed to cause the difference in their frost susceptibility classification even though they were both expected to be frost safe based on the requirements in Danish road regulations.

(5) To ensure that problems with frost heaving of sub-base gravel as fill in Pearl-Chain Bridges are entirely prevented, it is necessary to perform frost heave tests on the sub-base gravel used in their fill. In the freeze-thaw test setup used in this study the specimens were watersaturated and constantly fed with water from below; however, this represents a conservative scenario for Pearl-Chain Bridges because water is expected to drain off the superstructure. Thus, if the sub-base gravel is not frost susceptible according to the applied test procedure it is not expected that any problems arise with frost heaving of the fill material in Pearl-Chain Bridges; however, if the sub-base gravel is frost susceptible it is particularly important to ensure that the drainage of the superstructure is good.

\section{References}

Anderson, D.M., Williams, P.J., Guymon, G.L., and Kane, D.L., 1984. Principles of Soil Freezing and Frost Heaving. In: Berg, R.L., and Wright, E.A. eds. Frost action and its control. New York: American Society of Civil Engineers, 1-21, ISBN 0-87262-395-5.

ASTM Standard D2434-68, 2006. Standard Test Method for Permeability of Granular Soils (Constant Head). West Conshohocken, PA: ASTM International, DOI: 10.1520/D2434-68R06.

ASTM Standard D4253-16, 2016. Standard Test Methods for Maximum Index Density and Unit Weight of Soils Using a Vibratory Table. West Conshohocken, PA: ASTM International, DOI: 10.1520/D425316.

ASTM Standard D5918-13, 2013. Standard Test Methods for Frost Heave and Thaw Weakening Susceptibility of Soils. West Conshohocken, PA: ASTM International, DOI: 10.1520/D5918-13.

BEBO Arch Systems, 2009. Zürich: BEBO Arch Systems, Installation Guide. BEBO System Technical Documentation.

Beskow, G., 1935. Soil Freezing and Frost Heaving with Special Application to Roads and Railroads, trans. J.O. Osterberg. Evanston, IL: Technological Institute Northwestern University.

Casagrande, A., 1931. A new theory of frost heaving: discussion. Washington, DC: Highway Research Board, Vol. 11, 168-172, ISSN: 0096-1027.

Chamberlain, E.J., 1981. Frost susceptibility of soil. Review of index tests. Hanover, NH: U.S. Army Cold Regions Research and Engineering Laboratory, Monograph 81-2.

DS Standard 450-1, 2012. Fly ash for concrete - Part 1: Definition, specifications and conformity criteria. København: Danish Standards.

DS Standard 933-1, 2004. Tests for geometrical properties of aggregates - Part 1: Determination of particle size distribution - Sieving method. København: Danish Standards.

DS Standard 13285, 2011. Unbound mixtures - Specifications. København: Danish Standards.

DS Standard 13286-5, 2003. Unbound and hydraulically bound mixtures - Part 5: Test methods for laboratory reference density and water content - Vibrating table. København: Danish Standards.

DS Standard 13320, 2009. Particle size analysis - Laser diffraction methods. København: Danish Standards, Denmark.

Halding, P.S., Hertz, K.D., Petersen, N.E.V., and Kennedy, B., 2015. Assembly and lifting of Pearl-Chain Arches. Copenhagen: In Proceedings of fib Symposium, 18-20 May 2015, 185-186.

Hertz, K.D., Castberg, A., and Christensen, J., 2014. Super-light concrete decks for building floor slabs. Structural Concrete, Vol. 15, No. 4, 522-529, DOI: 10.1002/suco.201500062.

Hertz, K.D., 2015. Super-light SL-Deck elements with fixed end connections. Copenhagen: In Proceedings of fib Symposium, 18-20 May 2015, 465-466.

Hutchinson, D., 2004. Application and Design of Segmental Precast Arches. In: Yegian, M.K., and Kavazanjian, E., eds. Proceedings of GeoTrans, Los Angeles, California, July 27-31 2004. Reston, 
Table 1. Frost susceptibility criteria according to the ASTM D5918-13 standard (ASTM Standard D5918-13 2013).

\begin{tabular}{l|c}
\hline $\begin{array}{l}\text { Frost susceptibility } \\
\text { classification }\end{array}$ & $\begin{array}{c}\text { 8-h heave rate } \\
\text { [mm/day }]\end{array}$ \\
\hline Negligible & $<1$ \\
Very low & 1 to 2 \\
Low & 2 to 4 \\
Medium & 4 to 8 \\
High & 8 to 16 \\
Very high & $>16$ \\
\hline
\end{tabular}

VA: American Society of Civil Engineers, 452-459, ISBN: 978-0-7844-0744-8.

Lambe, T.W., and Whitman, R.V., 1969. Soil Mechanics. New York: John Wiley \& Sons, ISBN: 0-47151192-7.

Lund, M.S.M., Arvidsson, M., and Hansen, K.K., 2015. Homogeneity and Strength of Mortar Joints in Pearl-Chain Bridges. Copenhagen: In Proceedings of fib Symposium, 18-20 May 2015, 187-188.

Lund, M.S.M., Hansen, K.K., Truelsen, R., and Johansen, L. 2016. Pervious concrete fill in Pearl-Chain Bridges: Using small-scale results in full-scale implementation. Construction and Building Materials, Vol: 106, 404-414.

NCC Denmark. Road Construction - materials - wearing surfaces - pavements. 3rd ed. Copenhagen: NCC; 2001. Danish.

Rempel, A.W., 2007. Formation of ice lenses and frost heave. Journal of Geophysical Research, Vol. 112, F02S21, doi:10.1029/2006JF000525.

Rempel, A.W., 2010. Frost Heave. Journal of Glaciology, Vol. 56, No. 200, 1122-1128.

Sihwa, L., 1987. Computer Data Base Assessment of Masonry Bridges. Thesis (PhD). University of Edinburgh, UK.

Sub-base of Sand and Gravel - Design Guide, 2003. København: Tender specification, The Danish Road Directorate, ISBN: 87-7923-502-6 (In Danish).

Sub-base of Sand and Gravel - General Work Specification (GWS), 2003. København: Tender specification, The Danish Road Directorate, ISBN: 87-7923-503-4 (In Danish).

Taber, S., 1929. Frost Heaving. The Journal of Geology, Vol. 37, No. 5, 428-461.

Taber, S., 1930. The Mechanics of Frost Heaving. The Journal of Geology, Vol. 38, No. 4, 303-317.

\section{Appendix A. Criteria for determination of frost susceptibility according to the ASTM D5918-13 standard}

Table 1 shows the criteria given in the ASTM D5918-13 standard (ASTM Standard D5918-13 2013) to determine the degree of frost susceptibility of soil materials from their 8-hour heave rate. 